\title{
One more piece to SOLIDify our knowledge on the impact of SARS-CoV-2 in patients with cancer
}

\author{
Alfredo Addeo $^{1 \wedge}$, Alessio Cortellini ${ }^{2}$, Giuseppe Luigi Banna ${ }^{3}$ \\ ${ }^{1}$ Oncology Department, University Hospital Geneva, Geneva, Switzerland; ${ }^{2}$ Department of Surgery \& Cancer, Imperial College London, \\ Hammersmith Campus, London, UK; ${ }^{3}$ Candiolo Cancer Institute, FPO-IRCCS, Candiolo, Turin, Italy \\ Correspondence to: Alfredo Addeo. Oncology Department, University Hospital Geneva, Geneva 1205, Switzerland. Email: alfredo.addeo@hcuge.ch. \\ Comment on: Provencio M, Rodríguez-Abreu D, Ortega AL, et al. Seroprevalence and immunological memory against SARS-CoV-2 in lung cancer \\ patients: the SOLID study. Transl Lung Cancer Res 2022;11:53-63.
}

Submitted Feb 02, 2022. Accepted for publication Feb 23, 2022.

doi: $10.21037 /$ tlcr-22-93

View this article at: https://dx.doi.org/10.21037/tlcr-22-93

For the last 2 years our lives have been altered by a pandemic of coronavirus disease 2019 (COVID-19) caused by a new beta coronavirus, named severe acute respiratory syndrome coronavirus-2 (SARS-CoV-2) (1). It began in December 2019, spreading very soon to the rest of the world (2). Over the months, many data showed that patients with cancer were at high risk of mortality when infected with SARS-CoV-2, with up to $30 \%$ mortality in inpatient populations, particularly if affected by thoracic cancers (3). Several recommendations suggested measures to ensure the care of patients with thoracic cancers did not get deranged and regular hospitals visit were safe $(4,5)$.

Some selection bias might likely have played a role in this. Data were generated from patients admitted to the hospital due to COVID-19 complications, rather than from the entire population exposed to the virus. To address this aspect, the Spanish lung cancer group (SLCG) led by Provencio (6) ran a prospective, multicentre study offering serological tests to lung cancer patients who attended oncology appointments, either for follow-up or treatment, with a second determination 4.5 months after the first. The SOLID study aimed at prospectively determining seroprevalence in unselected lung cancer patients during the first wave of the pandemic, and the possible impact of treatments administered on the immunity persistence. One thousand five hundred patients were recruited within the study; 128 patients were seropositive $(8.5 \%)$ at the first time point. About $50 \%$ of the 128 patients had a history of illness due to
COVID-19. At the second time point, on average 4.5 months later, nearly $30.8 \%$ of the patients, previously seropositive, became negative, suggesting that natural infection protection might wane off over the months. In this series, only one patient $(0.8 \%)$ died of COVID-19, and there was no clear signal that specific anticancer treatment, either chemotherapy or immunotherapy, could impact the antibodies level.

Several important points come out of this study. As confirmed by similar series, the seroprevalence does not match the rate of patients who reported symptomatic SARS-CoV-2 infection, proving once again that SARS$\mathrm{CoV}-2$ infection could easily run asymptomatic (7). On the other hand, the SOLID study involved an outpatient population tested by a serological assay, which has proven high sensitivity and specificity two weeks after positive real time quantitative polymerase chain reaction (RT-qPCR) detection. These two aspects introduce a patient selection and lead-time bias. They refer to healthier patients with lung cancer than those receiving palliative care, who had not previously contracted a severe and potentially lethal SARS-CoV-2 disease and were treated in centres with different prevalences of the disease during the first wave of the pandemic. It could also explain the low mortality rate (of only 0.8 percent) observed among seropositive yet symptomatic patients than reported in the RT-qPCR confirmed disease. The second important aspect is the persistence of humoral immunity that might last over time without being influenced by lung cancer treatments

\footnotetext{
^ ORCID: 0000-0003-0988-0828.
} 
and the protection against reinfection. However, in about $30 \%$ of the patients, this humoral immunity got lost after 4.5 months, although no patients were reinfected. These figures are somewhat similar to what we have experienced nowadays with the vaccine. In a study comparing patients with solid tumours on treatment during the vaccination with the BNT162b2 vaccine to age-matched health care workers as controls, serology titer similarly decreased, with $79 \%$ patient and $84 \%$ controls being seropositive at 6 months, and no COVID-19 cases documented in controls but one in patients (8). Nonetheless, this information has to be put in the broader context of seroconversion in cancer patients. Serological response rates remain reduced in cancer patients compared to healthy controls, particularly those with haematological malignancies, and increase after boosting with repeated vaccine doses. Those remain crucial to minimise the risk of COVID-19 infection and severe complications in these vulnerable patients $(9,10)$. Similarly, evidence provided by the SOLID study that treatment type, either immunotherapy, chemotherapy, or their combination, and targeted agents may not affect the persistence of immunity, the mortality, or the reinfection rate caused by the COVID-19, in seropositive and symptomatic lung cancer patients is relevant and reassuring. However, it does not translate in a similar impact of treatments on seroconversion rate or potentially lethal complications of severe SARS-CoV-2 disease (11).

The third aspect concerns the COVID-19 variant factor. As a note, this study was run in 2020 when no anti-SARSCoV-2 vaccine was available, and a COVID-19 variant led the disease with different transmission capacity and aggressiveness from that is currently circulating or will do in the future. Therefore, it might seem not easy to contextualise the SOLID study data (6). Nevertheless, the data we have commented on reassured us that anticancer treatments have no impact on the persistence of humoral immunity and on the risk of developing a more severe COVID-19 in seropositive patients, which should apply to either the infected or vaccinated lung cancer population. They also showed that this immunity could get lost in about $30 \%$ of the patients irrespectively of their treatment. Interpreting the presence and the level of antibodies, $\operatorname{IgG}$ anti-N and anti-S as protection remains rather disputable, and no clear cut-off has been fully validated so far. In conclusion, we firmly believe that all patients with lung cancer should be fully vaccinated and boosted to ensure better protection against the newest strains of the SARS$\mathrm{CoV}-2$.

\section{Acknowledgments}

Funding: None.

\section{Footnote}

Provenance and Peer Review: This article was commissioned by the editorial office, Translational Lung Cancer Research. The article did not undergo external peer review.

Conflicts of Interest: All authors have completed the ICMJE uniform disclosure form (available at https://tlcr.amegroups. com/article/view/10.21037/tlcr-22-93/coif). AA received speakers' fees from Astrazeneca, Roche, Bristol Myers Squib, Merck, Pfizer, Eli LiLLy, Jansenn, Astellas, Sanofi; serves as speaker's bureau for Novartis, Astrazeneca, Eli LiLLy. AC received speakers' fees from Astrazeneca, EISAI and Novartis and grant consultancies from Astrazeneca, MSD, BMS and Roche. GLB received speaker or advisory board fees by Astellas and AstraZeneca. The authors have no other conflicts of interest to declare.

Ethical Statement: The authors are accountable for all aspects of the work in ensuring that questions related to the accuracy or integrity of any part of the work are appropriately investigated and resolved.

Open Access Statement: This is an Open Access article distributed in accordance with the Creative Commons Attribution-NonCommercial-NoDerivs 4.0 International License (CC BY-NC-ND 4.0), which permits the noncommercial replication and distribution of the article with the strict proviso that no changes or edits are made and the original work is properly cited (including links to both the formal publication through the relevant DOI and the license). See: https://creativecommons.org/licenses/by-nc-nd/4.0/.

\section{References}

1. Lu H, Stratton CW, Tang YW. Outbreak of pneumonia of unknown etiology in Wuhan, China: The mystery and the miracle. J Med Virol 2020;92:401-2.

2. Zhu N, Zhang D, Wang W, et al. A Novel Coronavirus from Patients with Pneumonia in China, 2019. N Engl J Med 2020;382:727-33.

3. Desai A, Gupta R, Advani S, et al. Mortality in hospitalized patients with cancer and coronavirus disease 2019: A systematic review and meta-analysis of cohort studies. 
Cancer 2021;127:1459-68.

4. Banna G, Curioni-Fontecedro A, Friedlaender A, et al. How we treat patients with lung cancer during the SARS$\mathrm{CoV}-2$ pandemic: primum non nocere. ESMO Open 2020;5:e000765.

5. Passaro A, Addeo A, Von Garnier C, et al. ESMO Management and treatment adapted recommendations in the COVID-19 era: Lung cancer. ESMO Open 2020;5:e000820.

6. Provencio M, Rodríguez-Abreu D, Ortega AL, et al. Seroprevalence and immunological memory against SARSCoV-2 in lung cancer patients: the SOLID study. Transl Lung Cancer Res 2022;11:53-63.

7. Dan JM, Mateus J, Kato Y, et al. Immunological memory to SARS-CoV-2 assessed for up to 8 months after infection. Science 2021;371:eabf4063.

Cite this article as: Addeo A, Cortellini A, Banna GL. One more piece to SOLIDify our knowledge on the impact of SARS-CoV-2 in patients with cancer. Transl Lung Cancer Res 2022;11(2):132-134. doi: 10.21037/tlcr-22-93
8. Waldhorn I, Holland R, Goshen-Lago T, et al. Six-Month Efficacy and Toxicity Profile of BNT162b2 Vaccine in Cancer Patients with Solid Tumors. Cancer Discov 2021;11:2430-5.

9. Addeo A, Shah PK, Bordry N, et al. Immunogenicity of SARS-CoV-2 messenger RNA vaccines in patients with cancer. Cancer Cell 2021;39:1091-8.e2.

10. Tran S, Truong TH, Narendran A. Evaluation of COVID-19 vaccine response in patients with cancer: An interim analysis. Eur J Cancer 2021;159:259-74.

11. Banna GL, Cantale O, Friedlaender A, et al. Risk of SARS-CoV2-related mortality in non-small cell lung cancer patients treated with first-line immunotherapy alone or in combination with chemotherapy. Cancer Invest 2021. [Epub ahead of print]. doi: 10.1080/07357907.2021.1970761. 